\title{
Differences in antibody levels to $H$. pylori virulence factors VacA and CagA among African Americans and whites in the Southeast USA
}

\author{
Julia Butt $^{1,2} \cdot$ William J. Blot $^{3} \cdot$ Martha J. Shrubsole $^{3} \cdot$ Tim Waterboer $^{2} \cdot$ Michael Pawlita $^{2} \cdot$ Meira Epplein $^{1}$
}

Received: 27 November 2019 / Accepted: 13 March 2020 / Published online: 28 March 2020

(c) The Author(s) 2020

\begin{abstract}
Purpose Helicobacter pylori (H. pylori) is the leading cause of gastric cancer. High antibody levels to H. pylori virulence factors Vacuolating cytotoxin A (VacA) and Cytotoxin-associated gene A (CagA) have been suggested as gastric cancer risk markers. In the USA, H. pylori sero-prevalence is twofold higher in African Americans compared to whites. We sought to assess whether African Americans also exhibit higher antibody levels to VacA and CagA.

Methods Antibody responses to H. pylori proteins were measured by multiplex serology in 686 African Americans and whites of the Southern Community Cohort Study. Among VacA- and CagA-seropositives, we analyzed the association of race with antibody level using logistic regression models to produce odds ratios (OR) and 95\% confidence intervals (CI).

Results Sero-positive African Americans had significantly higher mean antibody levels to both VacA and CagA, which resulted in increased odds for the highest quartile of antibody levels compared to sero-positive whites (VacA, OR: 6.08; 95\% CI 3.41, 10.86; CagA, OR: 3.77; 95\% CI 1.61, 8.84).

Conclusion Our findings support future studies to assess the association of differential antibody responses by race with risk of gastric cancer in the USA, which could then aid in developing targeted H. pylori eradication strategies.
\end{abstract}

Keywords Helicobacter pylori $\cdot$ Serology $\cdot$ Antibody level $\cdot$ Disparity

Julia Butt

julia.butt@duke.edu

William J. Blot

william.j.blot@vumc.org

Martha J. Shrubsole

martha.shrubsole@vumc.org

Tim Waterboer

t.waterboer@dkfz-heidelberg.de

Michael Pawlita

m.pawlita@dkfz-heidelberg.de

Meira Epplein

meira.epplein@duke.edu

1 Cancer Control and Population Health Sciences Program, Duke Cancer Institute and Department of Population Health Sciences, Duke University, Durham, NC, USA

2 Infection and Cancer Epidemiology, German Cancer Research Center, Heidelberg, Germany

3 Division of Epidemiology, Department of Medicine, Vanderbilt University Medical Center, Nashville, TN, USA

\section{Introduction}

Helicobacter pylori (H. pylori) infection is the leading cause of gastric cancer. Infection with $H$. pylori causes gastritis, which may become chronic. This chronic inflammation in turn leads to morphological changes in the gastric epithelium transitioning from chronic atrophic gastritis to intestinal metaplasia, dysplasia, and, in 1-3\% of $H$. pylori-infected individuals, to gastric cancer [1]. It is not fully resolved to date why only a proportion of infected individuals develop cancer and ongoing research targets biomarkers to identify individuals at increased gastric cancer risk early along the cascade of events leading to carcinogenesis. Serology provides an easy-to-apply non-invasive methodology and indeed $H$. pylori sero-positive individuals, and more specifically those sero-positive to virulence factors Vacuolating cytotoxin $\mathrm{A}(\mathrm{VacA})$ and Cytotoxin-associated gene A (CagA), were found to be at an approximately twofold to fourfold increased risk of developing gastric cancer [2,3]. Some studies have evaluated the antibody response to $H$. pylori quantitatively and results indicate that level of antibody response adds information beyond sero-positivity 
alone. High antibody levels were found to be associated with gastric mucosal inflammation, grade of histological gastritis, mucosal bacterial density, and gastric cancer risk [4-6].

H. pylori infects the stomach mucosa in approximately half of the world's population with varying prevalence by geographic region and population [7]. In the USA, for instance, the overall $H$. pylori sero-prevalence was $31 \%$ among adults aged 20 years or older in a national survey from 1999 to 2000 . However, the prevalence varied by race, with 52\% among African Americans compared to $21 \%$ among whites [8]. This largely reflects the disparity in non-cardia gastric cancer incidence, the gastric cancer sub-type most strongly associated with $H$. pylori, for which the age-standardized incidence rate for 1995 to 2013 was 6.43 in African Americans and 2.16 per 100,000 personyears in whites [9]. Moreover, gastric cancer accounts for the greatest racial disparity in mortality from cancer, being over twofold higher in African Americans compared to whites, suggesting the need for improved screening and prevention strategies [10, 11]. Despite the significantly higher $H$. pylori sero-prevalence in African Americans compared to whites, there are no reports available whether African Americans also exhibit higher level of antibody response. In the present study, we sought to assess whether African Americans are more likely to have higher antibody levels to VacA and CagA than whites in the Southeast USA.

\section{Methods}

\section{Study population}

The SCCS is a prospective cohort study that recruited approximately 86,000 men and women aged 40 to 79 from 12 southeastern US states at community health centers (CHCs) (86\%) or by mail (14\%) between 2002 and 2009 [12]. Participants completed a survey and about half of those recruited at $\mathrm{CHCs}$ provided a blood sample at baseline. We retrieved stored blood samples from the original $2 \times 2 \times 3 \times 3$ factorial design, whereby 792 individuals were randomly selected from the 12,162 SCCS participants with a blood sample given at baseline who were enrolled from March 2002 to October 2004, with strata defined by self-reported race (African American, white), sex (male, female), smoking status (never, former, current), and body mass index (BMI, $18-24.9,25-29.9,30-45 \mathrm{~kg} / \mathrm{m}^{2}$ ) [13]. Of these, 686 participants were included in the present analysis as the available serum was depleted from other assays performed on this group for 77 (9.7\%), samples for three $(0.4 \%)$ individuals were unusable because of serum handling issues, three individuals $(0.4 \%)$ were missing information on antibiotic use, and the ancestry estimates for 23 (2.9\%) were highly discordant with self-reported race, implying potential data entry errors. Fifty microliters of serum were aliquoted and sent to the German Cancer Research Center (DKFZ, Heidelberg, Germany) on dry ice for multiplex serology analysis.

\section{H. pylori multiplex serology}

Antibody responses to $15 \mathrm{H}$. pylori proteins (GroEl (strain G27), UreA, HP0231, NapA, HP0305, CagM, CagD, CagA, HpaA, Catalase, HyuA, VacA, Cad, HcpC, HP1564 (all strain 26695)) were measured by multiplex serology [13, 14]. H. pylori proteins were recombinantly expressed as GST-tag fusion proteins and affinity-purified on fluorescent polystyrene beads (Luminex Corp., Austin, TX, USA). A mixture of the differently labeled antigen-loaded beads was incubated with serum and the amount of bound serum antibody was quantified using a biotin-labeled secondary anti-human $\mathrm{IgG} / \mathrm{IgA} / \operatorname{IgM}$ antibody and subsequent labeling with streptavidin-R-phycoerythrin. A Luminex flow cytometer (Luminex Corp., Austin, TX, USA) then distinguished the bead-type and consequently the bound antigen as well as quantified the amount of bound serum antibody on at least 100 beads per type measured with the median fluorescence intensity (MFI) as output. Antigen-specific cut-offs were defined as described previously [13] and overall $H$. pylori sero-positivity was defined as being sero-positive to at least 4 of the 15 proteins included. Five replicate samples from each of two randomly selected individuals were analyzed for antibody responses to all $15 \mathrm{H}$. pylori proteins as quality control. We observed only one discordant result among the five replicate samples of one of the quality control individuals in sero-positivity to antigen HP0231. All other results replicated concordantly for both quality control individuals.

\section{Statistical analysis}

Differences in $H$. pylori sero-status and study characteristics between African Americans and whites were assessed using Chi-squared test for categorical variables and Wilcoxon rank-sum test for continuous variables.

Since antibody levels to VacA and CagA were not normally distributed, we calculated geometric means and $95 \%$ confidence intervals (CI) among $H$. pylori-antigen seropositive individuals and compared these by race applying t-tests. In addition, antibody responses to Vac A and CagA were divided into quartiles based on the distribution of these levels among all $H$. pylori-antigen-positive individuals (not race-specific). The association of race (African Americans compared to whites) with increasing antibody level quartile as outcome was then compared to the lowest quartile using unconditional logistic regression models to produce odds ratios (OR) and 95\% CI. Factors considered a priori as potentially relating to level of an individual's immune response and therefore considered to be included in the model were 
original stratification factors sex, BMI, and smoking, as well as a medication history of regular aspirin intake and antibiotics use within one year prior to recruitment, and other socio-demographic factors including socio-economic status (education and household income) and the participant's age [15-20]. Excluding the factors by which this population was stratified by (sex, BMI, and smoking status), all other factors except for regular aspirin intake were significantly different by race and were included in the model to test for the association of antibody level to VacA and CagA with adjustment for these factors. We finally present three models: (a) unadjusted, (b) adjusted for sex (male, female), BMI (18-24.9, $25-29.9,30-45 \mathrm{~kg} / \mathrm{m}^{2}$ ), and smoking status (never, former, current), (c) additional to adjustment in model b) adjusted for age (continuous), education ( $<$ High school, High school/GED, $>$ High school), household income $(<\$ 15,000$, $\$ 15,000-<\$ 25,000, \geq \$ 25,000)$, and antibiotics use during the past year before recruitment (yes/no). Five participants were lacking information on household income and where therefore excluded from model (c).

\section{Results}

In univariate analysis, African Americans were significantly younger than whites and more likely to have a lower educational level and household income per year but less likely to having taken antibiotics within the past year before recruitment (Table 1). With respect to H. pylori, African Americans were more likely to be overall $H$. pylori sero-positive than whites (89\% versus $69 \%$, respectively), and among $H$. pylori sero-positives, the sero-prevalence of VacA and CagA was also higher among African Americans than among whites (VacA sero-positivity $94 \%$ vs. $88 \%$, respectively; CagA sero-positivity $75 \%$ vs. $36 \%$, respectively) (Table 1). Among these $H$. pylori-antigen sero-positive study participants, African Americans had significantly higher average antibody levels than whites to VacA (African Americans, geometric mean MFI (95\% CI): 2,330 (2,079, 2,611); whites, geometric mean MFI (95\% CI): 1,165 (998, 1,359), $P<0.001$ ) and CagA (African Americans, geometric mean MFI (95\% CI): 18,228 (17,044, 19,494); whites geometric mean MFI (95\% CI) 12,783 (10,941, 14,831), $P<0.001)$ (Table 1).

When analyzed in quartiles, this resulted in significantly increased odds for high antibody levels in $H$.
Table 1 Study characteristics of whites and African Americans in the Southern Community Cohort Study factorial design

\begin{tabular}{|c|c|c|}
\hline & Whites & African Americans \\
\hline Age, [years], median $(\mathrm{IQR})^{\mathrm{a}}$ & $52(45,60)$ & $49(45,57)$ \\
\hline \multicolumn{3}{|l|}{ Education, $n(\%)^{\mathrm{b}}$} \\
\hline$<$ High school & $90(26)$ & $120(35)$ \\
\hline High school/GED & $139(41)$ & $141(41)$ \\
\hline$>$ High school & $111(33)$ & $85(25)$ \\
\hline \multicolumn{3}{|l|}{ Household income $[\$], n(\%)^{\mathrm{b}}$} \\
\hline$<15,000$ & $205(61)$ & $208(61)$ \\
\hline $15,000-<25,000$ & $62(18)$ & $84(24)$ \\
\hline$\geq 25,000$ & $71(21)$ & $51(15)$ \\
\hline \multicolumn{3}{|l|}{ Medication use } \\
\hline Antibiotics within last year yes, $n(\%)^{\mathrm{b}}$ & $187(55)$ & $148(43)$ \\
\hline Regular Aspirin intake yes, $n(\%){ }^{\mathrm{b}}$ & $278(82)$ & $301(87)$ \\
\hline \multicolumn{3}{|l|}{ H. pylori sero-status } \\
\hline Overall H. pylori,$+ n(\%)^{\mathrm{b}}$ & $234(69)$ & $308(89)$ \\
\hline VacA + among H. pylori,$+ n(\%)^{\mathrm{b}}$ & $206(88)$ & $291(94)$ \\
\hline $\begin{array}{l}\text { Antibody level [MFI], geometric mean (95\% } \\
\text { CI) }^{\mathrm{c}}\end{array}$ & $1165(998,1359)$ & $2330(2079,2611)$ \\
\hline CagA + among H. pylori,$+ n(\%)^{\mathrm{b}}$ & $85(36)$ & $232(75)$ \\
\hline $\begin{array}{l}\text { Antibody level [MFI], geometric mean (95\% } \\
\text { CI })^{\mathrm{c}}\end{array}$ & $12,738(10,941,14,831)$ & $18,228(17,044,19,494)$ \\
\hline
\end{tabular}

\footnotetext{
${ }^{+}$Sero-positive; $B M I$ body mass index; $C a g A$ cytotoxin-associated gene A; $C I$ confidence interval; $G E D$ general education development; IQR interquartile range; VacA Vacuolating cytotoxin A

${ }^{\text {a }} P<0.05$ in Wilcoxon rank-sum test

${ }^{\mathrm{b}} P<0.05$ in Chi-square test

${ }^{\mathrm{c}} P<0.05$ in Student's $t$ test
} 
pylori-antigen-positive African Americans compared to whites (Q4 versus Q1: VacA, OR: 5.40; 95\% CI 3.14, 9.29; Q4 versus Q1: CagA, OR: 4.34; 95\% CI 2.04, 9.26). These associations were significantly above and beyond adjustment for matching variables BMI, smoking and sex (Q4 versus Q1: VacA, OR: 5.81; 95\% CI 3.32, 10.18; Q4 versus Q1: CagA, OR: 4.24; 95\% CI 1.93, 9.31), as well as other sociodemographic and medical history factors that might affect the immune response to pathogens further including age, socio-economic status, and antibiotics use prior to recruitment (Q4 versus Q1: VacA, OR: 6.08; 95\% CI 3.41, 10.86; Q4 versus Q1: CagA, OR: 3.77; 95\% CI 1.61, 8.84) (Fig. 1).

\section{Discussion}

In the present study, we report that not only sero-prevalence to $H$. pylori significantly differs by race in a predominantly low-income population in the southern US but that also the level of antibody response to virulence factors CagA and VacA among sero-positives is higher in African Americans than whites in this population. This association remained significant even after adjustment for factors potentially interfering with the host's immune response, including smoking, BMI, sex, socio-economic status as a measure of stress, antibiotic use, and the participant's age [15-20].

To our knowledge, this is the first study in African Americans compared to whites to look at the level of humoral immune response to $\mathrm{H}$. pylori, and more specifically its virulence factors VacA and CagA, and our findings may lead to further research questions in the interest
Fig. 1 Association of race with antibody level to VacA and CagA among $H$. pylori-antigenpositive individuals. The association of African American race compared to whites being in the higher antibody quartile $(\mathrm{Q} 2, \mathrm{Q} 3$, and Q4) in reference to $\mathrm{Q} 1$ was determined using logistic regression models to compute odds ratios (OR) and $95 \%$ confidence intervals (CI). Model (a): unadjusted; model (b): adjusted for sex (male, female), BMI (18-24.9, $\left.25-29.9,30-45 \mathrm{~kg} / \mathrm{m}^{2}\right)$, and smoking status (never, former, current); model (c): additional adjustment for age (continuous), education ( $<$ High school, High school/GED, $>$ High school), household income $(\$,<15,000$, $15,000-<25,000, \geq 25,000$ ), and antibiotics use during the past year before recruitment (yes/no). Quartile borders (Q1, Q2, Q3, Q4) were based on the overall sample set among $H$. pylori and antigenpositives (VacA: Q1: 200-712 MFI, Q2: > 712-1915 MFI, Q3:> 1915-4063 MFI, Q4: > 4063 MFI; CagA: Q1: 3091-14,475, Q2: > 14,47521,079, Q3:>21,079-26,219, Q4:>26,219)

\begin{tabular}{|c|c|c|c|c|c|}
\hline & $\begin{array}{c}\text { Whites } \\
\text { n (\%) }\end{array}$ & $\begin{array}{c}\text { African } \\
\text { Americans } \\
\mathrm{n}(\%)\end{array}$ & & OR & $95 \% \mathrm{Cl}$ \\
\hline \multicolumn{6}{|c|}{$H P+V a c A+(n=497)$} \\
\hline \multicolumn{6}{|l|}{ Model a } \\
\hline Q1 & $85(41)$ & $40(14)$ & $\phi$ & 1.00 & (Ref) \\
\hline Q2 & $56(27)$ & $68(23)$ & 一 & 2.58 & $(1.54-4.32)$ \\
\hline Q3 & $30(15)$ & $94(32)$ & $\longrightarrow$ & 6.66 & (3.82-11.62) \\
\hline Q4 & $35(17)$ & $89(31)$ & - & 5.40 & $(3.14-9.29)$ \\
\hline \multicolumn{6}{|l|}{ Model b } \\
\hline Q1 & $85(41)$ & $40(14)$ & $\phi$ & 1.00 & (Ref) \\
\hline Q2 & $56(27)$ & $68(23)$ & & 2.64 & $(1.56-4.48)$ \\
\hline Q3 & $30(15)$ & $94(32)$ & & 7.03 & $(3.96-12.47)$ \\
\hline Q4 & $35(17)$ & $89(31)$ & & 5.81 & (3.32-10.18) \\
\hline \multicolumn{6}{|l|}{ Model c } \\
\hline Q1 & $85(41)$ & $40(14)$ & $\phi$ & 1.00 & (Ref) \\
\hline Q2 & $56(27)$ & $68(23)$ & & 2.85 & $(1.63-4.97)$ \\
\hline Q3 & $30(15)$ & $94(32)$ & & 7.10 & $(3.92-12.88)$ \\
\hline Q4 & $35(17)$ & $89(31)$ & & 6.08 & $(3.41-10.86)$ \\
\hline \multicolumn{6}{|c|}{$H P+C a g A+(n=317)$} \\
\hline \multicolumn{6}{|c|}{ Model a } \\
\hline Q1 & $35(41)$ & $45(19)$ & $\phi$ & 1.00 & (Ref) \\
\hline Q2 & $18(21)$ & $61(26)$ & & 2.64 & $(1.33-5.24)$ \\
\hline Q3 & $20(24)$ & $59(25)$ & & 2.29 & $(1.17-4.50)$ \\
\hline Q4 & $12(14)$ & $67(29)$ & & 4.34 & $(2.04-9.26)$ \\
\hline \multicolumn{6}{|l|}{ Model b } \\
\hline Q1 & $35(41)$ & $45(19)$ & $\phi$ & 1.00 & (Ref) \\
\hline Q2 & $18(21)$ & $61(26)$ & & 2.63 & $(1.28-5.43)$ \\
\hline Q3 & $20(24)$ & $59(25)$ & & 2.53 & (1.24-5.17) \\
\hline Q4 & $12(14)$ & $67(29)$ & & 4.24 & $(1.93-9.31)$ \\
\hline \multicolumn{6}{|l|}{ Model c } \\
\hline Q1 & $35(41)$ & $45(19)$ & $\phi$ & 1.00 & (Ref) \\
\hline Q2 & $18(21)$ & $61(26)$ & & 2.42 & $(1.12-5.26)$ \\
\hline Q3 & $20(24)$ & $59(25)$ & & 2.36 & $(1.09-4.96)$ \\
\hline \multirow[t]{3}{*}{ Q4 } & $12(14)$ & $67(29)$ & & 3.77 & $(1.61-8.84)$ \\
\hline & & & 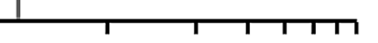 & & \\
\hline & & & $\begin{array}{lll}6 & 8 & 14\end{array}$ & & \\
\hline
\end{tabular}


of examining and remediating racial health disparities. It has been previously described that the inflammatory response to certain pathogens is stronger in African Americans than in whites [21] and that level of circulating pro-inflammatory cytokines also varies by race [22], which may have implications for inflammation-related outcomes like gastric cancer. Therefore, our findings warrant clarification of whether increased antibody levels in African Americans also relate to stronger host inflammatory responses being an important factor in gastric carcinogenesis. Bacterial factors that should be considered in this respect include bacterial load, and the isoform of virulence factor (e.g., allotypes $\mathrm{s} 1 \mathrm{~m} 1, \mathrm{~s} 1 \mathrm{~m} 2$, and $\mathrm{s} 2 \mathrm{~m} 2$ for VacA and different CagA EPIYA motifs) as well as the amount of virulence factor expressed. Ultimately, it needs to be elucidated whether these factors may contribute to the racial disparity in gastric cancer incidence and mortality in the USA [10].

Although the present study's design with matching on race, sex, BMI, and smoking status allowed us to assess the association of antibody level to $H$. pylori virulence factors VacA and CagA and controlled for factors that might impact the host's immune response, the study also had limitations. The measure of antibiotic treatment within the past year before recruitment was self-reported and the influence of antibiotic treatment on antibody level therefore might have been underestimated in this study. Moreover, the H. pylori sero-prevalence in the investigated population was above the national average for African Americans (89\% versus 52\%) and whites (69\% versus $21 \%$ ), likely due to the predominantly low socio-economic status of the SCCS cohort, and results may therefore not be generalizable [8]. These findings therefore would need to be validated in an independent study. Additionally, differences in access to care may relate to differences in antibody levels, as racial differences in appropriate testing for H. pylori among symptomatic patients have been found [23]; however, as the vast majority of individuals with chronic $H$. pylori infection are asymptomatic, we do not think this would account for the significant results found.

In conclusion, we found that among $H$. pylori seropositive individuals in the SCCS, African Americans had significantly higher levels of antibody response to both VacA and CagA compared to whites. Future studies will need to assess the association of the observed differential antibody response to the main gastric cancer related $H$. pylori virulence factors $\mathrm{CagA}$ and VacA with an increased risk of developing gastric cancer in the USA, which could then aid in developing targeted $H$. pylori eradication strategies for populations with increased gastric cancer risk.

Acknowledgements Open Access funding provided by Projekt DEAL.
Funding The Southern Community Cohort Study (SCCS) is funded by grant U01 CA202979 from the National Cancer Institute at the National Institutes of Health. SCCS data collection was performed by the Survey and Biospecimen Shared Resource which is supported in part by the Vanderbilt-Ingram Cancer Center (P30 CA68485).

Open Access This article is licensed under a Creative Commons Attribution 4.0 International License, which permits use, sharing, adaptation, distribution and reproduction in any medium or format, as long as you give appropriate credit to the original author(s) and the source, provide a link to the Creative Commons licence, and indicate if changes were made. The images or other third party material in this article are included in the article's Creative Commons licence, unless indicated otherwise in a credit line to the material. If material is not included in the article's Creative Commons licence and your intended use is not permitted by statutory regulation or exceeds the permitted use, you will need to obtain permission directly from the copyright holder. To view a copy of this licence, visit http://creativecommons.org/licenses/by/4.0/.

\section{References}

1. Correa P, Houghton J (2007) Carcinogenesis of Helicobacter pylori. Gastroenterology 133:659-672

2. Epplein M, Zheng W, Xiang YB et al (2012) Prospective study of Helicobacter pylori biomarkers for gastric cancer risk among Chinese men. Cancer Epidemiol Biomark Prev 21:2185-2192

3. Gao L, Michel A, Weck MN, Arndt V, Pawlita M, Brenner H (2009) Helicobacter pylori infection and gastric cancer risk: evaluation of $15 \mathrm{H}$. pylori proteins determined by novel multiplex serology. Cancer Res 69:6164-6170

4. Shiota S, Murakami K, Okimoto T, Kodama M, Yamaoka Y (2014) Serum Helicobacter pylori CagA antibody titer as a useful marker for advanced inflammation in the stomach in Japan. $\mathbf{J}$ Gastroenterol Hepatol 29:67-73

5. Tu H, Sun L, Dong X et al (2014) Serum anti-Helicobacter pylori immunoglobulin $\mathrm{G}$ titer correlates with grade of histological gastritis, mucosal bacterial density, and levels of serum biomarkers. Scand J Gastroenterol 49:259-266

6. Yoshida T, Kato J, Inoue I et al (2014) Cancer development based on chronic active gastritis and resulting gastric atrophy as assessed by serum levels of pepsinogen and Helicobacter pylori antibody titer. Int J Cancer 134:1445-1457

7. Hooi JKY, Lai WY, Ng WK et al (2017) Global prevalence of Helicobacter pylori infection: systematic review and meta-analysis. Gastroenterology 153:420-429

8. Grad YH, Lipsitch M, Aiello AE (2012) Secular trends in Helicobacter pylori seroprevalence in adults in the United States: evidence for sustained race/ethnic disparities. Am J Epidemiol 175:54-59

9. Anderson WF, Rabkin CS, Turner N, Fraumeni JF Jr, Rosenberg PS, Camargo MC (2018) The changing face of noncardia gastric cancer incidence among US Non-Hispanic Whites. J Natl Cancer Inst 110:608-615

10. Ashktorab H, Kupfer SS, Brim H, Carethers JM (2017) Racial disparity in gastrointestinal cancer risk. Gastroenterology 153:910-923

11. DeSantis CE, Miller KD, Goding Sauer A, Jemal A, Siegel RL (2019) Cancer statistics for African Americans, 2019. CA Cancer J Clin 69:211-233

12. Signorello LB, Hargreaves MK, Steinwandel MD et al (2005) Southern community cohort study: establishing a cohort to investigate health disparities. J Natl Med Assoc 97:972-979 
13. Epplein M, Signorello LB, Zheng W et al (2011) Race, African ancestry, and Helicobacter pylori infection in a low-income United States population. Cancer Epidemiol Biomark Prev 20:826-834

14. Michel A, Waterboer T, Kist M, Pawlita M (2009) Helicobacter pylori multiplex serology. Helicobacter 14:525-535

15. Padgett DA, Glaser R (2003) How stress influences the immune response. Trends Immunol 24:444-448

16. Scepanovic P, Alanio C, Hammer C et al (2018) Human genetic variants and age are the strongest predictors of humoral immune responses to common pathogens and vaccines. Genome Med 10:59

17. Sopori M (2002) Effects of cigarette smoke on the immune system. Nat Rev Immunol 2:372-377

18. Stepanikova I, Bateman LB, Oates GR (2017) Systemic inflammation in midlife: race, socioeconomic status, and perceived discrimination. Am J Prev Med 52:S63-S76

19. Struve J, Aronsson B, Frenning B, Granath F, von Sydow M, Weiland O (1992) Intramuscular versus intradermal administration of a recombinant hepatitis B vaccine: a comparison of response rates and analysis of factors influencing the antibody response. Scand $\mathrm{J}$ Infect Dis 24:423-429

20. Weber DJ, Rutala WA, Samsa GP, Santimaw JE, Lemon SM (1985) Obesity as a predictor of poor antibody response to hepatitis B plasma vaccine. JAMA 254:3187-3189

21. Nedelec Y, Sanz J, Baharian G et al (2016) Genetic ancestry and natural selection drive population differences in immune responses to pathogens. Cell 167:657-669e21

22. Yao S, Hong CC, Ruiz-Narvaez EA et al (2018) Genetic ancestry and population differences in levels of inflammatory cytokines in women: role for evolutionary selection and environmental factors. PLoS Genet 14:e1007368

23. Florea A, Brown HE, Harris RB, Oren E (2019) Ethnic disparities in gastric cancer presentation and screening practice in the United States: analysis of 1997-2010 surveillance, epidemiology, and end results-medicare data. Cancer Epidemiol Biomark Prev 28:659-665

Publisher's Note Springer Nature remains neutral with regard to jurisdictional claims in published maps and institutional affiliations. 